\title{
DON MIGUEL DE UNAMUNO, UN DISIDENTE ANTE LAS CORTES CONSTITUYENTES DE LA SEGUNDA REPUBLICA
}

\author{
Alfonso Carlos Saiz Valdivielso \\ Profesor Titular de Derecho Constitucional \\ Universidad de Deusto
}

... José Ortega y Gasset y Gregorio Marañón se sientan junto a Unamuno en la Cámara Constituyente. Buscan, aún, con agonía y con garbo juvenil el contacto con el espíritu huidizo y versátil de la Asamblea. Don Miguel ya no busca nada de eso. Está solo y esperando...

Profecía para 1932: Don Miguel de Unamuno, hartado de soledad, abrirá el trueno y soltará el rayo...

Víctor DE LA SERNA Crónicas Parlamentarias

Diciembre de 1931

... No hay disciplina de partido que pueda someter la conciencia de un ciudadano. Esto es verdaderamente indigno. La disciplina de partido termina, siempre, donde empieza la conciencia de las propias convicciones...

Miguel de UnAmuno Discurso en las Cortes Constituyentes 23 de junio de 1932

Sumario: I. Plano de situación personal y preludio periodístico. II. Diálogo y confrontación de las Lenguas. III. Constitución y Autonomías. IV. Enseñanza, idioma y libertad de expresión. V. Addenda. Constitución y República. VI. Conclusión.

\section{Plano de situación personal y preludio periodístico}

Concejal electo el 12 de abril de 1931, don Miguel de Unamuno es nombrado alcalde honorario del Ayuntamiento de Salamanca el día 16. Dos días después, el Claustro universitario salmanticense le nombrará Rector.

El día 27 de aquel abril de 1931 es nombrado Presidente del Consejo de Instrucción Pública. 
Le quedan a don Miguel tres años para su jubilación académica. Está, pues, en la última vuelta de su camino.

Fernando Vela, que dirige $E l \mathrm{Sol}$, requiere su colaboración periodística para el rotativo madrileño, en el que no hace mucho José Ortega y Gasset dejó estampada su «delenda est monarchia ${ }^{1} »$.

Unamuno comienza su colaboración periodística en El Sol el 13 de mayo con un artículo titulado «Pleito de historia y no de sociología», que se agavilla con otros dos más, todos ellos bajo el epígrafe La promesa de España ${ }^{2}$.

Este preludio periodístico de don Miguel viene a plantear algunos de los problemas más acuciantes que van a nacerle a la incipiente República. Recuerda su actitud antimonárquica desde el destierro decretado por la dictadura del General Primo de Rivera. Sostiene que las formas de Gobierno son accidentales, mientras que las personas que las encarnan son sustanciales. De ahí su argumento de que el pleito de Monarquía o República sea más cosa de Historia que de Sociología, para proclamar, seguidamente: «Y si hemos traído a la mayoría de los españoles el republicanismo, ha sido por antialfonsismo, por reacción contra la política imperialista y patrimonialista del último Habsburgo de España...»

Advierte sobre la no conveniencia de una separación tajante de la Iglesia y el Estado, manifestándose proclive a la libertad de cultos, y a que se subvencione a la Iglesia católica, sin que ello signifique una situación privilegiada, configurándose una Iglesia española sometida al Estado, pero no separada de éste ${ }^{3}$.

La problemática agraria llama, igualmente, su atención, por su anómala estructura: amplios latifundios en la parte más despoblada y proliferación minifundista allí donde se produce una mayor concentración humana.

Pero la gran cuestión de estos primeros artículos periodísticos, que será «leit-motiv» recurrente durante todo el periodo 1931-1933, desde la pluma, la tribuna pública y la sede parlamentaria, es la unidad nacional. La vertebración española empieza a percibirse por la opinión pública como una dialéctica entre lo federal y lo unitario. Rechaza Unamuno que unitario equivalga a centralista, y en cuanto al concepto federal: «Hay que saber que lo que en España se llama, por lo común, fe-

${ }^{1}$ Fue el 15 de noviembre de 1930, en el artículo titulado «El error Berenguer», determinante de su salida del periódico fundado por Nicolás Urgoiti.

2 El tríptico se publicó los días 13, 14 y 15 de mayo de 1931.

${ }^{3}$ En el artículo «Comunismo, Fascismo, reacción clerical y problema agrícola», El Sol, 14 de mayo de 1931. 
deralismo, tiene muy poco del federalismo de The Federalist o New Constitution de Hamilton, Jay y Madison... Lo que aquí se llama federar es desfederar, y no unir lo que está separado».

La opción federalista, invocada por determinados sectores políticos, como posible solución a las tensiones entre el poder central del Estado y los nacionalismos peninsulares, es rechazada tajantemente por el Rector de Salamanca al negar los postulados irredentistas en que aquéllos se apoyan: «... Eso de que Cataluña, Vasconia y Galicia hayan sido oprimidos por el Estado español no es más que un desatino...» ${ }^{4}$

Poco antes de que el proceso electoral otorgue carta de naturaleza al nuevo Régimen, nacido de unas elecciones municipales, Unamuno desde la atalaya periodística de $\mathrm{El} \mathrm{Sol}$, reflexiona sobre el divorcio ${ }^{5}$, que acabaría constitucionalizándose en el artículo 43 de la carta magna republicana.

Desde el punto de vista jurídico, no le interesa «porque no siendo yo ni siquiera Licenciado en Derecho, carezco de clientela de bufete de abogado en que se me podría presentar el caso», y en cuanto a su necesidad se muestra así de radical: «Me parece que obedece más que a ansias de los malmaridados, a una especie de sentimiento anticanónico o, si se quiere, anticlerical respecto al matrimonio ${ }^{6}$. Estas son cosas de lo que llamamos burguesía, y de la aristocracia. El que se llama, por antonomasia, pueblo, no se preocupa apenas del divorcio. Es problema que al verdadero proletario, al que tiene que cuidar de su prole, no se le suele presentar. Y es que en el proletario, en el obrero, la igualdad de los sexos es mayor que en otras clases. Téngase en cuenta las familias obreras, en que la mujer es más sostén de ellas que el marido».

Tras las elecciones generales del 28 de junio, don Miguel obtiene una de las siete actas de diputado a Cortes por Salamanca ${ }^{7}$.

Más que presentarse a la elección, le han presentado los sectores republicanos de la ciudad con el respaldo de los socialistas ${ }^{8}$.

${ }^{4}$ En «Los comuneros de hoy se han alzado contra el descendiente de los Austrias y Borbones», El Sol, 15 de mayo de 1931.

5 El Sol, 13 de junio de 1931.

${ }^{6}$ En esta actitud, cuenta mucho el sentido familiar de Unamuno, hondamente vivido.

7 Las otras seis correspondieron a Filiberto Villalobos, médico; Tomás Marcos Escribano, presidente de la Diputación; Primitivo Santa Cecilia, tipógrafo y alcalde de Salamanca; José M. ${ }^{a}$ Gil Robles, abogado; Cándido Casanueva, propietario, y José M. ${ }^{a}$ Lamamié de Clairac, terrateniente. (En Emilio SAlcedo, Vida de don Miguel. Anthema Ediciones, Salamanca 1998, pp. 387-388).

8 Pedro Cerezo Galán, Las máscaras de lo trágico (Filosofía y tragedia en Miguel de Unamuno). Edit. Trotta, Madrid 1996, p. 762. 
Nueva reflexión periodística, de hondo calado político. Cuatro ideas esenciales que habrán de desatar honda polémica en los meses venideros. Se contienen en el título Nación, Estado, Iglesia, Religión ${ }^{9}$. Cuatro pilares para estructurar la convivencia, o cuatro proyectiles para destruirla. Según se mire.

Escribe Unamuno en el citado artículo:

«... No puede confundirse la nación con el Estado o reducirse a éste. Si hay palabra ambigua es esta del Estado, con la que juegan federales, comunistas, anarquistas, sindicalistas, y sus adversarios y contradictores...»

«... El Estado es la corporación de los que ejercen el poder público, la burocracia a que viven sujetos los llamados Gobiernos. El Estado viene a ser a la nación lo que la clerecía a la Iglesia...»

«... Eso de que la religión es un asunto puramente individual o privado resulta, históricamente, un error. La religión, sea la que fuere, es un lazo entre individuos, un lazo que religa...»

A una semana de la apertura de las Cortes, Unamuno encara la situación autonomista que llegará, en su momento, a la Cámara como una asignatura pendiente, impulsada por los nacionalistas. Formula la cuestión como una teoría del resentimiento. El Estatuto o los desterrados de sus propios lares $^{10}$, es el primer toque de atención sobre un asunto que hará correr ríos de tinta en la prensa, y desatará huracanes verbales en el Parlamento:

«... Yo que había tratado a algunos irlandeses sinn feinens ("nosotros mismos"), esos sedicentes celtas, quejumbros del arpa y la verdura, cuando alcanzaron su independencia de Inglaterra, me dije: $Y$ ahora que no les queda ya resentirse de Inglaterra, ¿qué van a hacer?...»

Buen punto de partida para discurrir acerca de las pretensiones de quienes apadrinan el Estatuto vasco-navarro de Estella ${ }^{11}$, para fustigar, en toda regla, la intención que encierra su contenido, de cuya inviabilidad está plenamente convencido:

9 Artículo publicado en El Sol, el 2 de julio de 1931.

10 El Sol, 7 de julio de 1931.

11 Integrantes de una coalición o conjunción liderada por José Antonio de Aguirre, en la que se alinean, católicos neutros, católicos fueristas, jaimistas e integristas, cuyos nombres más significativos son José M. ${ }^{a}$ de Urquijo, Marcelino Oreja Elósegui, José Luis de Oriol y el canónigo Pildain. (Alfonso Carlos SAIz VALDIVIELso, Triunfo y Tragedia del periodismo vasco. Ed. Nacional, Madrid 1977, pp. 241-246 y «Religión y política en el Estatuto Vasconavarro de Estella», en Historia Internacional, n. ${ }^{\circ}$ 12, marzo de 1976). 
«... El Estatuto, por lo que de él conozco, es algo, en gran parte, deliciosamente infantil, y no habrá daño para mis paisanos liberales en que fuera aprobado por España, pues las más absurdas de sus prescripciones $^{12}$ no podrán nunca llevarse a la práctica. Se resistirán a ellas los mismos a los que se les quiere aplicar, y si se intentara forzarles a seguirlas, acabarían por sentirse advenedizos todos los indígenas... Y es que hay nacionalismos chicos con los que sólo se consigue hacer que uno se sienta desterrado de su propia tierra, forasteros en su propio hogar y cuna, ahogado en aldeanerías sin patria civil...»

La repercusión de este artículo en los sectores de la conjunción republicano-socialista acaudillada en Bilbao por Indalecio Prieto, se hizo notar de inmediato ${ }^{13}$.

El 16 de julio, el diputado por Salamanca Miguel de Unamuno y Jugo, vasco por los cuatro costados y español medular, formula una distinción entre República española y España republicana ${ }^{14}$, juego de palabras que sirven de pretexto para insistir en su valoración sobre las formas políticas y sobre la consideración de la ciudadanía:

«... Ni la Monarquía, ni la República son sustancias, sino formas y ni siquiera formas sustanciales, como los escolásticos le llamaban al alma, de la que decían que era la forma sustancial del cuerpo...» «... Y no achiquemos nación a un sentido lugareño, de lugar más o menos rico en vecindario, pues ni vecino es, sin más, ciudadano...»

En vísperas del primer otoño republicano, y de sus primeras intervenciones parlamentarias, Unamuno redacta y publica uno de sus artículos más contundentes de esta época. Su título, Sobre el cavernicolismo ${ }^{15}$, es un ejercicio de metáfora en el que cabe una múltiple reflexión jurídico-política e histórica sobre la Constitución y otros elementos adyacentes, en la que el oficio de lingüista se pone de manifiesto:

«... La Historia es la base de toda la Constitución del Estado — con mayúsculas- que es cosa minúscula al lado de la constitución de la na-

12 La fijación de plazos discriminatorios para acceder a la ciudadanía vasca dependiendo del lugar de nacimiento, o la reserva competencial para concordar con el Vaticano, entre otras. (Artículo 3. ${ }^{\circ}$ a, y Apartado Cuarto del artículo 15).

13 El Liberal, de Bilbao, 16, 17 y 18 de julio de 1931.

14 El Sol, 16 de julio de 1931. Llamamos la atención sobre este título por haber servido a Vicente González Martín para dar nombre a su edición y comentarios sobre los artículos de Unamuno publicados entre 1931 y 1936 (Ediciones Almar, Salamanca, 1979), no recogidos en las obras completas de don Miguel.

15 El Sol, 12 de septiembre de 1931. 
ción — con minúscula de nombres comunes-. Lo uno no es más que jurídico; lo otro es político...»

«... Estado y Estatuto, vienen de status, acto de ponerse y de estarse en pie; es la situación de lo que está en pie, y statuere, estatuir, es poner en pie algo...»

«... Nación deriva de nacer, y popularmente "ciego de nación" quiere decir ciego de nacimiento...»

«... La constitución nacional, la historia, es la acción de componerse y constarse juntos, en pie y en un haz, los nacidos en común, en comunidad de destino ${ }^{16} \ldots$ Y ésta es la historia de España desde que es España y sobre todo desde los Reyes Católicos, desde que con la toma de Granada y el descubrimiento de América se anuda, por voluntad divina, por la gracia de Dios, la unidad nacional española...»

«... Esa íntima constitución nacional se ha intentado prostituirla, ponerla a subasta y regateo cantonales por instintos prehistóricos, troglodíticos y cavernícolas...»

«... Los leyendarios, primeros fundadores de la sociedad civil, los soñados contratantes y pactantes ${ }^{17}$, no son más que un mal sueño, una pesadilla, y están fuera de la Historia...»

«... El troglodita de la cueva de Altamira, el que trazó aquel mágico bisonte, al que se ha tragado el león de España, no vivía en la historia, no vivía la historia, y no podía pactar, ni contratar nada...»

«.. ¿Derechos individuales? Para que los haya, el individuo tiene que ser persona y el pobre troglodita no lo era...»

\section{Diálogo y confrontación de las lenguas}

El 11 de septiembre de 1931, Unamuno encabeza con su firma una enmienda al artículo $4^{\circ}$ del proyecto constitucional redactado por la Comisión, en el siguiente tenor:

«El castellano es el idioma oficial de la República, sin perjuicio de los derechos que las leyes del Estado reconocen a las diferentes provincias o regiones».

La enmienda unamuniana, suscrita también por José Ortega y Gasset, Pedro Suárez Uriarte, Alfonso García Valdecasas, Justino Azcárate, José

16 Esta idea de «comunidad de destino» de Unamuno y la de «proyecto sugestivo de vida en común» de ORTEGA, en España invertebrada, nutren los conceptos de José Antonio Primo de Rivera al definir España como «unidad de destino en lo universal».

17 Alusión a Juan Jacobo RouSSEAU y su Contrato Social. El desdén hacia el ginebrino será compartido, años más tarde, por José Antonio en sus primeras palabras del acto fundacional de Falange Española en el madrileño Teatro de la Comedia (29 de octubre de 1933). 
Fernando González Uña, Juan Díaz del Moral y Bernardo Giner de los Ríos propone:

«El español es el idioma oficial de la República. Todo ciudadano español tiene el deber de saberlo y el derecho de hablarlo. En cada región se podrá declarar cooficial la lengua de la mayoría de sus habitantes. A nadie se podrá imponer, sin embargo, el uso de ninguna lengua regional» ${ }^{18}$.

Se avecina una polémica lingüística. Buen tema para filólogos, y Unamuno lo es.

Con tal motivo va a formalizarse la primera intervención parlamentaria en las Constituyentes republicanas, que tendrá lugar en la sesión del 18 de septiembre de $1931^{19}$.

Le precede en el uso de la palabra Alfonso Rodríguez Castelao que, también ese día, hace su presentación en sede parlamentaria, con un discurso emotivo y cordial en defensa de la lengua gallega. Desea Castelao que el gallego sea tan español como el castellano, subrayando una declaración política de intenciones:

«... No somos separatistas, porque si separatista viene de separar, separatista será el que no quiera que el gallego sea, también, un idioma español...»

Llegado su turno, Unamuno estructura un alegato pasional a favor de la lengua española, en un apabullante alarde de conocimiento de las demás lenguas de España, invocadas desde su expresión literaria. Buena ocasión para evocar aquel celebérrimo y controvertido discurso que, como mantenedor de unos Juegos Florales, pronunció en el Teatro Arriaga de su Bilbao ${ }^{20}$ :

«... Hace cosa de treinta años, allí en mi tierra nativa pronuncié un discurso que produjo una gran conmoción, un discurso en el que les dije a mis paisanos que el vascuence estaba agonizante, que no nos quedaba más que recogerlo y enterrarlo con piedad filial, embalsamado en ciencia.

18 Apéndice $4 .^{\circ}$ al n. ${ }^{\circ} 37$ del Diario de Sesiones de las Cortes Constituyentes —en adelante DSCC — de 11 de septiembre de 1931.

19 Jean Becarud, en Miguel de Unamuno y la Segunda República, Taurus, Madrid 1965, pp. 15-17, da, erróneamente, como fecha del primer discurso parlamentario de Unamuno la del 25 de septiembre de 1931. La referencia parlamentaria del primer discurso se consigna en el DSCC núm. 41 del día 18 de septiembre de 1931, pp. 1.015-1.020.

20 Fue el 26 de agosto de 1901. 
Provocó aquello una gran conmoción, y una mala alegría fuera de mi tierra, porque no es lo mismo hablar en una mesa a los hermanos, que hablar a los otros. Creyeron que puse en aquello una intención que no puse. Hoy continúa esa agonía; es cosa triste, pero el hecho es un hecho, y así como me parecería una verdadera impiedad el que se pretendiera despenar a alguien que se está muriendo, a la madre moribunda, me parece tan impío inocularle drogas para alargarle una vida ficticia, porque drogas son los trabajos que hoy se realizan para hacer una lengua culta, y una lengua que, en el sentido que se da ordinariamente a esta palabra, no puede llegar a serlo...»

En su negación de la unidad euskérica, aporta como argumento el caso de sus abuelos que, como sus padres, eran vascoparlantes, resultando que dos de ellos apenas podían entenderse entre sí porque uno era vizcaíno y el otro guipuzcoano.

Invoca a Iñigo de Loyola «el hombre más grande que ha tenido nuestra raza» que no escribió en lengua vasca sus Ejercicios, incidiendo en que «no hay un alto espíritu vasco, ni en España, ni en Francia, que no se haya expresado en castellano o en francés...»

Rebate la manida acusación nacionalista de que Castilla no conoce la periferia:

«... Y yo os digo que la periferia conoce mucho peor a Castilla, que hay pocos espíritus más comprensivos que el castellano...»

Cuando habla de Galicia cita a Curros Enríquez y los Aires da miña terra, reprochándole afectivamente su victimismo, su tono de quejumbrosidad, afirmando que Rosalía de Castro «cuando quiso encontrar la mujer universal, que era una alta mujer, no la encontró en aquellas coplas gallegas, la encontró en sus poesías castellanas de La orilla del Sar...»

Cuando llega el turno a Cataluña, evoca su amistad con Joan Maragall y los versos del gran poeta:

Escolta Espanya la veu d'un fill que't parla en llengua no castellana, parlo en la llengua que m'ha donat la terra aspra en questa llengua, pocs t'han parlat; en l'altra..., massa...

Y le atribuye un español lleno de enjundia y vigor, superior incluso al de Jaime Balmes, o al de Francisco Pi y Margall.

Recuerda que el catalán, que tuvo una espléndida florescencia literaria hasta el siglo $\mathrm{XV}$, enmudeció entonces como lengua de cultura, $\mathrm{y}$ 
mudo permaneció durante los siglos del Renacimiento, de la Reforma y la Revolución, «volviendo a renacer hará cosa de un siglo»:

«... Hoy se encarga de su renovación un hombre de gran competencia y sobre todo de una exquisita probidad intelectual y de una gran honradez científica como es Pompeyo Fabra...»

Vuelve al eje central de su enmienda, ese «no se podrá imponer a nadie», aunque renuncia a matizarla hasta el momento en que se discuta la cuestión de la Enseñanza:

«... Trataremos de cómo el Estado español tendrá que tener en las regiones autónomas quien obligue a saber castellano, y sé que si mañana hay una Universidad castellana, mejor española, con superioridad, siempre prevalecerá sobre la otra; es más, ellos mismos la buscarán. Os digo más, y es que cuando no se persiga su lengua, ellos empezarán a hablar y a querer conocer la otra...»

Unamuno hace un punto y aparte para referirse a la conquista lingüística de Valencia, «la patria del más grande poeta catalán Ausías March, donde Ramón Muntaner escribió su maravillosa Crónica, de donde salió Tirant lo Blanc».

Se lamenta de que el gran poeta valenciano Vicente Wenceslao Querol quisiera escribir en lemosin «que era una cosa artificial y artificiosa, y no su lengua natal, sino una lengua de Juegos Florales»:

«... Claro que cuando tenía que sacar el alma de Valencia, no lo hacía en la Lengua de Jaime de Aragón, sino en la del Cid de Castilla, y para convencerse no hay más que leer el poema Ausente, que ningún buen valenciano debe leer sin que se le empañen los ojos de lágrimas...»

Acto seguido, metaforiza el comienzo del libro de los Hechos de los Apóstoles «como unas Cortes Constituyentes de la primitiva Iglesia cristiana, el Pentecostés»:

«... Cuando sopló como un eco el Espíritu vivo, vinieron lenguas de fuego sobre los apóstoles, se fundió todo el pueblo, hablaron en cristiano, y cada uno oyó en su Lengua y en su dialecto: sulamitas, persas, medos, frigios, árabes, egipcios... Y esto es lo que he querido hacer al traer aquí un eco de todas esas lenguas; porque yo que subí a las montañas costeras de mi tierra vasca a secar mis huesos - los del cuerpo y los del alma-, y en tierra castellana fui a enseñar castellano a los hijos de Castilla, he dedicado largas vigilias, durante largos años al estudio de las Lenguas todas de la patria, y a enseñarlas, que todos mis discípulos han salido iniciados en el conocimiento del castellano, del 
galaico-portugués y del catalán ${ }^{21}$... Y yo a mi vez me recreaba en esas Lenguas para hacerme la mía propia, para rehacer el castellano, haciéndolo español, recreándome en él. Y esto es lo que importa...»

Toma la palabra a Gabriel Alomar que le ha precedido en la sesión y aborda su idea de nación:

«... Yo también, amigo Alomar, en estos días de renacimiento, he pensado en eso y me ha venido la palabra precisa: España no es nación, es renación: renación de renacimiento, de renacer allí donde se funden todas las diferencias, donde desaparece esta triste y pobre personalidad diferencial...»

Tales palabras hicieron mella entre los catalanistas, galleguistas y minoría vasco-navarra en la que se integraban los nacionalistas vascos.

Así, Jaime Carner defiende la cooficialidad del catalán en mérito de un hecho consumado: haberse incorporado ya al texto estatutario.

Ramón Otero Pedrayo, por su parte, insiste a favor de un galleguismo integrador.

Finalmente, Jesús María de Leizaola, diputado del PNV, integrado en la coalición estatutista vasco-navarra, hará valer la vitalidad y progreso de la lengua vasca frente a las tesis regresivas de Unamuno.

Conviene no dejar de lado, en la crónica de esta primera comparecencia parlamentaria de Unamuno, su punto de vista sobre los continuamente invocados «hechos diferenciales» en función del idioma:

«... Se está hablando siempre de nuestras diferencias interiores. Esto es cosa de gente que, o no viaja, o no se entera de lo que ve. En el aspecto lingüístico, hay naciones de Europa como Italia y Francia que tienen más diferencias que España. En Italia no sólo hay una multitud de dialectos de origen románico, sino que se habla alemán en el Alto Adigio, esloveno en el Friul, albanés en ciertos pueblos del Adriático, y griego en algunas islas. En Francia pasa lo mismo. Además de los dialectos de las lenguas latinas, tienen el bretón y el vasco...»

$\mathrm{Ni}$ tampoco el cierre esteticista, justificador de su presencia en la Cámara:

«... La Lengua, después de todo, es precisa, y si un Código pueden hacerlo sólo juristas que suelen ser, por lo común, doctores de la letra muerta, creo que para hacer una Constitución, que es algo más que un Código, hace falta el concurso de los líricos, que somos los de la palabra viva...»

21 Obsérvese que excluye el euskera que conocía, pero que nunca enseñó. 


\section{Constitución y Autonomías}

La sesión del 25 de septiembre, centra o quizá descentra la discusión parlamentaria en torno al contenido del artículo 12 del proyecto constitucional que trata de las competencias del poder del Estado en relación con las de las Regiones autónomas.

Sesión tumultuosa en la que, una vez más, salen a relucir los «hechos diferenciales» junto a presuntas promesas hechas por los republicanos a los catalanistas en el célebre y críptico Pacto de San Sebastián, sobre el cual, y en su momento, el eminente jurista Felipe Sánchez Román, liberal y desvinculado de opciones concretas de partido, se expresó rigurosamente ${ }^{22}$.

El problema autonómico se balancea entre debates y enmiendas, en una tensión que a veces apunta hacia la soberanía compartida por las regiones y el Estado. Se apostaba, también, por un federalismo pimargalliano que no se había revisado desde hacía sesenta años. Se ignoraba que el federalismo no supone el Estado, sino la aspiración de crearlo a partir de otros Estados preexistentes, y que lo específico de su idea se reduce exclusivamente al problema de la soberanía.

José Ortega y Gasset, que barrunta lúcidamente el disparate a que puede conducir la improvisación y la indefinición conceptual, ha proclamado que «la soberanía no es una competencia cualquiera, no es propiamente un poder, no es ni siquiera el Estado, sino que es el origen de todo poder, de todo Estado, y, en él, de toda ley... ${ }^{23}$

En aquella sesión del 25 de septiembre se han mostrado partidarios del federalismo, los federalistas propiamente dichos, los nacionalistas vascos, los de la Federación Republicana Gallega y los catalanistas de Esquerra ${ }^{24}$.

Unamuno hace tronar su voz. Se indigna ante la desorientación e imprecisiones del Gobierno al que para salir del atolladero autonómico

${ }^{22}$ Sánchez Román en la Sesión del 4 de septiembre de 1931 dejó bien sentado que: «En aquel pacto de San Sebastián, hubo lo único que podía haber: la designación de un procedimiento para traer con el mayor prestigio y con la mayor garantía el problema catalán al Parlamento. Y por eso el pacto de San Sebastián acordó, como síntoma demostrativo de su esencialidad, estas dos estipulaciones: Primera, que Cataluña, antes de la decisión del Parlamento, practicaría justamente lo que ha practicado en cuanto a la formación de su Estatuto, y no algo que ha practicado y que no estaba previsto en el pacto, ni autorizado por el pacto mismo; Segunda que el Parlamento resolvería soberanamente y que la resolución que tomase el Parlamento español sería acatada rigurosamente por los elementos políticos de Cataluña representados en el pacto...»

23 DSCC núm. 40 de 17 de septiembre de 1931.

${ }^{24}$ Las voces más significadas fueron las de Luis Companys (Esquerra), Franchy Roca (Minoría federal), Jesús M. ${ }^{a}$ de Leizaola (PNV), Alfonso R. Castelao (FRG). 
no se le ha ocurrido nada mejor que señalar que la cuestión estatutista no es otra cosa que un mero trámite, que no se prejuzga nada, que se trata tan sólo de evitar que se obstruyan ciertos problemas, que ha de tomarse en consideración el plebiscito que ha respaldado el Estatuto de Cataluña:

«... Por lo que veo, de lo que aquí se trata es de ver si sale el Estatuto a remolque de la Constitución, o sale la Constitución a remolque del Estatuto...»

«... El plebiscito se ha hecho muchas veces. Un pueblo, por una especie de plebiscito condenó a muerte a Sócrates sin razón, y quince días después, aquel mismo pueblo, sin más razón, había querido resucitarle. La voluntad de un pueblo no es tan fácil de conocer, sobre todo cuando no se le puede ilustrar, suficientemente, respecto de aquello sobre lo que tiene que decidir...»

En alusión al dichoso pacto de San Sebastián, «de dicho, no de dicha», fustiga el mercadeo de los intervinientes y sus alardes de patrocinadores de la República:

«... Yo no sé lo que en el pacto se convino; parece que los que tomaron parte en él lo saben demasiado bien. De todos modos en aquel pacto no entró para nada el país. Entraron unos hombres que nos dicen que han traído la República, pero ha de saberse que la República no la trajeron los del pacto, sin pacto habría venido lo mismo, acaso mejor. Quien propiamente trajo la República fue don Alfonso de Borbón y Habsburgo...»

Hace mella, en buena parte del hemiciclo y en el banco azul, la diatriba unamuniana a la que aún le queda recorrido. Desdeña la férrea disciplina de partido:

«... Aquí al servicio de la República me encuentro libre de algo que se llama disciplina de los partidos. Oigo a mucha gente decir: "Sí, mi convicción es ésta, pero en la reunión del partido se ha acordado una cosa contraria”. ¡Como si la opinión de partido pudiera estar sobre la convicción individual, cuando se trata de servir el interés de España...»

Repudia la forma parlamentaria en que se está elaborando el texto constitucional, a la que no es ajena la responsabilidad de los partidos políticos, consumidos por un prurito de precipitación y de prisa, enemigo de la reflexión y la cordura. No le falta razón a don Miguel al denunciar el ejercicio de confusión parlamentaria en el que los dictámenes 
de la Comisión se hacen en el Pleno, sometiendo a las Constituyentes a una fatiga atormentante:

«... No se puede sacar una Constitución con fórceps, que resultan muy peligrosos no ya para la vida de la criatura, sino para la vida de la madre. Por eso, cuando aquí se habla de la República recién nacida, y de los cuidados que necesita, yo digo que más cuidados necesita la madre que es España, que si al fin muere la República, España puede parir otra nueva, pero si muere España, no hay República posible...»

Bien puede asegurarse que con estas palabras Unamuno ha marcado su actitud disidente, que habrá de despertar serios recelos en buena parte de quienes apoyaron su elección hasta que don Miguel abandone sus tareas parlamentarias.

No comprende que en estos debates se contraponga Cataluña y España, o Vasconia y España, o Galicia y España:

«... No me explico este distingo. Es como decir "la cabeza y todo el cuerpo", "el corazón y todo el cuerpo", o "el estómago y todo el cuerpo"... Ojalá en esta lucha quisieran los catalanes catalanizar toda España, como mis paisanos, los vascos, vasquizar toda España...» ${ }^{25}$

En la recta final de su discurso, un párrafo de insistencia sobre su no militancia política:

«... Nosotros no trajimos la República; la República nos ha traído. Pero hay más: a mí se me requirió para traerme a este escaño, a mí se me requirió para venir aquí, cuando yo, en ninguna forma lo solicitaba, no por ningún partido, porque nunca he figurado en ningún partido...» ${ }^{26}$

${ }^{25}$ Estas palabras tienen reminiscencias de las pronunciadas en los bilbaínos Juegos Florales de 1901, cuando exhortó a sus paisanos: «iSi no queréis ser invadidos, invadid!»

Posteriormente en el artículo «Sobre el imperialismo» publicado en la revista Hispania, de Buenos Aires, el 16 de julio, de 1911, Unamuno escribía: «... Yo quiero, y lo quiero con toda mi alma de español, que mis paisanos los vascos traten de vasconizar España, y que traten de catalanizarla los catalanes... Pero, unos y otros, tendrán que hacerlo en castellano...»

26 No era verdad, por lo que a un pasado lejano se refiere, pues Unamuno ingresó, como afiliado, en la Agrupación Socialista de Bilbao en 1894, en la que permaneció hasta 1896. Durante esta etapa colaboró, frecuentemente, en el semanario La Lucha de Clases (Rafael PÉrez de la Dehesa, Política y Sociedad en el primer Unamuno: 1894-1904. Ed. Ciencia Nueva, Madrid 1966, p. 57).

A esto podría añadirse el comentario de Luis ARAQUISTAIN en El pensamiento español contemporáneo. Ed. Losada, Buenos Aires 1962, p. 68: «... Nadie en ese tiempo, hacia finales del siglo XIX, ni el propio Pablo Iglesias, el gran organizador del socialismo en España, ataca al sistema capitalista con más bello y vigoroso estilo...» 
Y otro, legitimador de la teoría del mandato representativo:

«... No me ha traído aquí Castilla, ni Salamanca. Yo no soy un diputado de Castilla; ni siquiera, en rigor, creo que me ha traído aquí la República, aunque sea hoy un diputado republicano. Aquí me ha traído España. Yo me considero un diputado de España» ${ }^{27}$.

El escándalo que Unamuno ha metido en el cuerpo del «republicanismo oficial y partidista», desde su escaño, va a incrementarse el primero de octubre, con motivo de la apertura del curso académico, en Salamanca.

A los cuarenta años de su llegada a la ciudad del Tormes, y a los treinta de un acto de la misma naturaleza como Rector, don Miguel dice a las autoridades políticas, académicas y a los estudiantes, que ni las Ciencias, ni las Artes, ni las Letras son monárquicas o republicanas; que la cultura está por encima y por debajo de las pequeñas diferencias contingentes, accidentales y temporales de las formas de Gobierno.

Exhorta a luchar por la libertad de la cultura, por su unidad y universalidad, por la pluralidad ideológica.

Las palabras rituales que ponen colofón al acto académico, siembran el desconcierto:

«En nombre de Su Majestad España, una, soberana y universal, declaro abierto el Curso de 1931-1932 en esta Universidad universal y española de Salamanca, y que Dios Nuestro Señor nos ilumine a todos para que, con su gracia, podamos en la República servirle, sirviendo a nuestra madre patria» ${ }^{28}$.

\section{Enseñanza, idioma y libertad de expresión}

El 22 de octubre se discute en las Cortes el artículo 48 del proyecto constitucional sobre la enseñanza del castellano en las distintas instancia docentes. El idioma, o mejor los idiomas, de nuevo, como objeto de controversia, de confrontación ${ }^{29}$.

27 DSCC núm. 45 del día 25 de septiembre de 1931, pp. 1.166-1.170.

28 Quienes malinterpretaron estas palabras en un republicano, tendrían que esperar al 14 de abril de 1932, para entender su significado. En la misma sede académica Unamuno explicó: «Saben los que tienen algún conocimiento de Humanidades que majestad es maiestas, mayestad, o sea mayoridad, es decir lo que está por encima de todo y corresponde a la soberanía. Y al decir "Su Majestad España" quería decir que no hay más soberanía que la de España, que la del pueblo español. Es lo que se llama soberanía popular, por la cual todos, en cuanto tengamos conciencia de ciudadanía y españolidad, todos seremos soberanos» (Emilio SALCEDO, op. cit., p. 405).

29 DSCC núm. 61 del día 22 de octubre de 1931, pp. 1.887-1.889. 
Don Miguel, bajo de salud y sobre todo de ánimo, sostiene que no es la lengua lo más grave de la cuestión. Más que lo propio de la cultura le preocupa la civilización, sobre todo a partir de tanta invocación, por parte de los nacionalistas de todas clases, de las «minorías étnicas». A tal efecto recuerda lo que en cierta ocasión aconteció cuando un alcalde de Barcelona se dirigió a Alfonso XIII en nombre de los naturales de Barcelona:

«... Yo me creí obligado a protestar. Un alcalde no puede dirigirse en nombre de los naturales, sino de los vecinos, sean naturales o no; ni se puede establecer una diferencia entre vecinos y naturales. No hay, no puede haber dos ciudadanías. Ese es el punto de la civilización... Yo no sé cuántos constituyen esa minoría étnica, por ejemplo, en Barcelona. No sé si son el diez, el veinte, el treinta o el cuarenta por ciento. Lo que me parece bochornoso es que se les vaya a proteger como a una minoría. ¡A proteger! El Estado no debe pasar por eso; a que le protejan otros y a que se les dé como una asignatura el castellano; como instrumento, no; como asignatura, no...»

Pone especial ardor en la defensa de la universidad estatal de Barcelona a la que no quiere ver bajo ningún otro poder que no sea el del Estado. No tiene reparos en denunciar un propósito solapado de apoderarse de la institución por el catalanismo, ni tampoco de recelar de la pretendida autonomía universitaria:

«... Llevo cuarenta años de profesor, y sé lo que sería de la mayor parte de nuestras Universidades si se dejara una plena autonomía, y cómo se convertirían en cotos cerrados para cerrar el paso a los forasteros. Además, yo que no entiendo mucho, ni quiero entender, de ciertas distinciones jurídicas, veo que hay una cosa que nunca comprendo bien, cuando se habla de catalanes y no catalanes. Para mí todo ciudadano español radicado en Cataluña, donde trabaja, donde vive, donde cría su familia, es no sólo ciudadano catalán, tan catalán como los otros. No puede haber dos ciudadanías».

Alude, en los tramos finales de su discurso, a la Constitución como estructura vital, no meramente formal, deslizando una idea constante en su pensamiento: la de «guerra civil» ${ }^{30}$ :

${ }^{30}$ La exaltación de la «guerra civil» es una constante en la obra de Unamuno, como verificación de las diferentes tensiones que subyacen en la vida individual y en la de los pueblos. Viene a decirnos que cada uno de nosotros, los hombres, es un yo colectivo, una sociedad, en que constantemente luchan entre sí diversos yos, y luchan por compenetrarse e integrarse bajo uno u otro de ellos, tanto en los pueblos como en las naciones (Una re- 
«... Por encima de esta Constitución de papel, está la realidad tajante y sangrante del país. Se quiere evitar cierta guerra civil (no una guerra civil cruenta, a tiros y a palos, naturalmente); me parece que va a ser muy difícil, y además no lo deploro. Hay ciertas fuerzas civiles que son las que hacen la verdadera unidad de los pueblos... Cualquier cosa que hagamos estará siempre en revisión, que es una cosa continua... Los periodos constituyentes no acaban nunca, y es una locura creer que porque pongamos una cosa en el papel, va a quedar ya hecha...»

Dos días después, vuelve su sarcasmo sobre la recién aprobada Ley de Defensa de la República ${ }^{31}$, en el artículo titulado En un perpetuo sábado, al señor B.C. $D^{32}$ :

«... Con que ya lo sabe usted, señor mío, es acto de agresión a la República, la apología del régimen monárquico. No se dice, precisamente, de la Monarquía, lo cual podrá a usted parecerle no más que una tontería; pero guárdese de emplear expresiones así, de menosprecio...»

«... Individualmente, me duelen menos los hechos que las explicaciones que de ellos dan sus apologistas. Lo peor de la República me parecen los republicanistas, que no son precisamente los republicanos...» ${ }^{33}$.

Concluye con una frase soberbia y lapidaria: «El Señor no me puso en esta España para dar facilidades a los cobardes».

Unamuno se aleja a pasos agigantados de la deriva sectaria de una República, cuyo sumo pontífice gobernante, Manuel Azaña, intelectual de Ateneo, inspirado por la beatería roussoniana, le repugna sobremanera. Y no se muerde la lengua ni aligera la pluma cuando protesta airadamente del artículo 3. ${ }^{\circ}$ de la Constitución que declara que el Estado español no tiene Religión oficial:

«... Declarad en el papel que no hay Religión del Estado; pero la hay nacional, y es la del pueblo, que vive de misteriosidades...»

ferencia importante sobre esta temática en Elías DíAz, Revisión de Unamuno. Análisis crítico de su pensamiento político. Ed. Tecnos, Madrid 1968, pp. 120-130. Otra, de mayor amplitud monográfica, en José Miguel DE AzAOLA, Unamuno y sus guerras civiles. Ed. Laga, Bilbao 1996).

31 Concretamente sobre el apartado 6 del artículo 10 de dicha Ley aprobada el 20 de octubre de 1931, que consideraba acto de agresión a la República «la apología del régimen monárquico o de las personas en que se pretenda vincular su representación, y el uso de emblemas, insignias o distintivos alusivos a uno u otras».

$32 \mathrm{El} \mathrm{Sol,} 24$ de octubre de 1931 (El destinatario consignado en iniciales es imaginario).

33 En alusión a la conjunción republicano-socialista que le respaldó con sus votos en las elecciones municipales del 12 de abril, y muy especialmente a los nacionalistas catalanes. 
En su alejamiento, el encuentro con otro desencantado, José Ortega y Gasset, que el 6 de diciembre pronuncia la célebre conferencia Rectificación de la República, donde se escucha del gran filósofo madrileño el famoso «No es eso» ${ }^{34}$.

No parece mejorar el pulso democrático en los comienzos de 1932. Por de pronto en la sesión parlamentaria del 6 de enero, cuando se discute la cuestión de los bienes de la Compañía de Jesús, el diputado Lamamié de Clairac intenta intervenir en defensa de los jesuitas, y no se le permite. Ante este atropello, Unamuno firma junto a Ossorio y $\mathrm{Ga}-$ llardo y Miguel Maura una enérgica protesta por el veto ${ }^{35}$.

No aflorará el verbo parlamentario de don Miguel hasta el mes de junio. Se discute el día 23 el dictamen sobre el artículo 2 del Estatuto de Cataluña.

La intervención de Unamuno está precedida de un agrio incidente parlamentario por no admitirse una enmienda presentada el día $16^{36}$.

Aún sin aceptarla, Barnés, Vicepresidente de la Cámara, da la palabra a Unamuno quien comienza su discurso dando lectura a la enmienda fallida, para explicar acto seguido que el motivo de la misma era oponerse a una parte del dictamen de la Ponencia según el cual «dentro del territorio catalán, los ciudadanos, cualquiera que sea su lengua materna tendrán derecho a elegir el idioma oficial que prefieran en sus relaciones con las autoridades y funcionarios de toda clase, tanto de la Generalidad como de la República».

${ }^{34}$ Conferencia pronunciada en el Cine Opera, de Madrid, que reproduce íntegra $\mathrm{El} \mathrm{Sol}$, el día 8, a la que asisten Ramón Pérez de Ayala, el Dr. Gregorio Marañón y Miguel Maura, entre otras personalidades.

35 DSCC del día 6 de enero de 1932.

${ }^{36}$ La enmienda, que no fue admitida porque ya se había empezado a discutir el artículo en cuestión, llevaba incorporadas, además de la de Unamuno, las firmas de Miguel Maura, Justino de Azcárate, José M. ${ }^{a}$ Santa Cruz, Felipe Sánchez Román, Alfonso García Valdecasas, Bernardo Giner de los Ríos y Antonio Sacristán. He aquí su texto:

«Artículo 2. ${ }^{\circ}$ El idioma catalán es, como el castellano, lengua oficial de Cataluña. Para las relaciones oficiales de Cataluña con el resto de España así como para la comunicación de las autoridades del Estado con Cataluña, la lengua oficial será el castellano. Toda disposición o resolución oficial dictada por los órganos regionales, en Cataluña, deberá ser publicada y, en su caso, notificada en ambos idiomas. Dentro del territorio catalán los ciudadanos tendrán derecho a elegir el idioma oficial que prefieran en sus relaciones con las autoridades y funcionarios de la Generalidad. De los documentos públicos autorizados en Cataluña se expedirá copia en catalán, a instancia de parte». 
Para Unamuno, aceptar este texto implicaba que si todos los ciudadanos pueden elegir el idioma oficial que prefieran en sus relaciones con las autoridades de la República, éstas, por deducción lógica, tendrían la obligación de conocer el catalán. Admite que ello sea conveniente, pero se opone a que sea obligatorio:

«..Si en un tiempo hubo aquello que, indudablemente, era algo más que grosero de "hable usted en cristiano", ahora puede suceder a la inversa: ¿No sabe usted catalán? Pues apréndalo, y si no, no intente gobernarnos aquí».

Unamuno es consciente de los votos que los catalanistas van a recibir de las izquierdas no catalanas, en función, básicamente, de la sintonía ideológica, no por convicción:

«... No hay disciplina de partido que pueda someter la conciencia de un ciudadano. Esto es verdaderamente indigno. La disciplina de partido termina, siempre, donde empieza la conciencia de las propias convicciones, y yo digo que tan desastroso es para los que rinden así su conciencia contra su convicción, como para los que acepten estos votos...» ${ }^{37}$.

Intervendrá también en la sesión del día siguiente, anunciando que le resultará difícil asistir a los próximos debates porque habrá sesiones nocturnas «y pasando las diez de la noche, yo no soy dueño de mí, y creo que la mayor parte de los diputados, pasando las once o las doce, no se enterarán de lo que se discute».

A lo intempestivo de los horarios alude, intencionadamente, para criticar el modo en que se discutió la Constitución y las circunstancias en que se aprobó, «apelando, incluso, a sesiones permanentes».

Sus últimas palabras inciden una vez más, en su animadversión a la partitocracia:

«... Se dice que qué manía tengo contra los partidos. En efecto. Si creo tener alguna autoridad es por representar una gran parte de opinión española, de la España entera y no partida, y me temo que si los partidos

37 DSCC núm. 188 de 23 de junio de 1932, pp. 6.414-6.416. Ese mismo día, Unamuno, Miguel Maura, Alfonso García Valdecasas, Felipe Sánchez Román, José M. ${ }^{a}$ Santa Cruz, Manuel Rico Avello, José F. González Uña y Bernardo Giner de los Ríos, presentan una enmienda de adición proponiendo un artículo $3 .^{\circ}$ con esta redacción: «El castellano será el idioma único para las relaciones internas de los organismos que, dentro de Cataluña, ejerzan funciones de la competencia exclusiva del Estado» (Apéndice 5. ${ }^{\circ}$ al número $188 \mathrm{del}$ DSCC de 23 de junio de 1932). 
se empeñan — que creo que no- en hacer cosas de ideología y de disciplina de problemas en que eso no puede hacerse, corren el riesgo de cambiar de sexo, es decir de convertirse de partidos en partidas, lo cual sería muy peligroso...» ${ }^{38}$

No volverá a las Cortes hasta el 2 de agosto. Su intervención en esta sesión, el último acto parlamentario de Unamuno, deriva de la enmienda presentada el 13 de julio por él, junto a Felipe Sánchez Román, Justino de Azcárate, Antonio Sacristán, Publio Suárez, Alfonso García Valdecasas y Luis García Lozano, al artículo 10 del dictamen de la Comisión del Estatuto de Cataluña ${ }^{39}$.

El centro neurálgico de su discurso constituye una crítica feroz al caótico estado de confusión al que ha llegado la Cámara sacudida por la presión de dictámenes, enmiendas y votos; una Cámara ajena a lo que ocurre fuera de ella.

Recuerda y reprocha las palabras de Azaña a Maura en la sesión de 22 de octubre de 1931 en torno al debate constitucional y al deber de transigir con las demandas catalanistas sobre el Estatuto ${ }^{40}$.

Se opone Unamuno a que se hagan concesiones mientras no se aquieten ciertas pasiones y no se ponga freno a quienes se manifiestan con temeraria imprudencia:

«... Yo declaro que hay quien grita en Cataluña - lo hacen también en mi tierra nativa - “¡Viva Cataluña libre!” Está muy bien, pero yo me preguntaría, ¿libre de qué? Porque eso, como el hablar de nacionalidades oprimidas — perdonadme la fuerza y la dureza de la expresiónes sencillamente una mentecatada. No ha habido nunca semejante opresión y lo demás es envenenar la Historia y falsearla...»

Advierte del peligro que puede entrañar otorgar facultades al Gobierno para que negocie con Cataluña. En este trance alguien replica:

38 DSCC del 24 de junio de 1932, pp. 6.450-6.452.

39 Cuyo texto proponía: «Es obligatorio el estudio de la lengua castellana que deberá emplearse como instrumento de enseñanza en todos los Centros de España. La Generalidad de Cataluña podrá, sin embargo, organizar enseñanzas en su lengua regional. Pero el Estado mantendrá, también, en Cataluña las instituciones de enseñanza de todos los grados en el idioma oficial de la República» (Apéndice 9. ${ }^{\circ}$ al núm. 200 del DSCC de 13 de julio de 1932).

40 Dijo Azaña en aquella sesión: «... ¿Cómo es posible que nosotros, al discutirse la Constitución, vayamos a adoptar un texto constitucional que haga imposible, el día de mañana, la votación libre del Estatuto de Cataluña, o el de cualquiera otra región, prejuzgando una cuestión que debe resolverse, en su esencia, al votarse esos Estatutos, y no la Constitución? Y teniendo nosotros, hombres de partido, la convicción de que no se roza para nada el porvenir de las atribuciones del Estado, estamos en el deber de transigir». 
«iAh, es que hay un compromiso!» Ha sido la gota que colma el vaso de la paciencia de don Miguel:

«... Cuando llegue el caso pida, quien quiera que sea. Hará muy bien. Deberá hacerlo la Generalidad, pero sean las Cortes, éstas u otras las que respondan, pero no un Gobierno, tenga los compromisos que quisiere, que podrá tenerlos; pero el país no tiene compromisos al respecto...»

No deben pasarse por alto, en este discurso, las palabras finales que tienen significación de ruptura:

«... Estoy harto de que cuando se adopta una posición que está en contra de la directiva del Gobierno, o de la mayoría, se diga que se va contra la República...»

Ha defendido don Miguel su libertad de expresión que El Sol no habrá de respetar al devolverle un artículo en el que entre otras cosas decía:

«... No daré un viva a la República, aún deseando que viva, mientras no se pueda dar un viva al Rey, a un Rey cualquiera ${ }^{41}$.

\section{Addenda. Constitución y República}

Don Miguel de Unamuno, Académico de la Lengua desde el 15 de diciembre de 1932, no volverá nunca más a las Cortes.

Su opinión se queda para la cátedra y para sus colaboraciones periodísticas a lo largo de 1933, año que excede del límite del presente trabajo.

El 12 de septiembre de aquel año Unamuno publica uno de sus artículos periodísticos más demoledores contra los gobernantes republicanos. Bajo el título de Constitución y República ${ }^{42}$ acumula agravios diversos contra el régimen, partiendo del por qué votó, en su condición de concejal, la candidatura agraria, contra la ministerial, para el Tribunal de Garantías Constitucionales. Explica cómo se pronunciaba con su voto, no contra la República, naturalmente, ni contra la Constitución «actualmente yacente, que no vigente», sino a favor de su revisión, al entender que si el Tribunal de Garantías Constitucionales ${ }^{43}$ cumple con

\footnotetext{
41 Su ruptura con El Sol el 30 de noviembre de 1932, por presión gubernamental, determina su colaboración con Ahora, que publica el artículo censurado «Y va otra vez de monodiálogo». Dos días antes ha pronunciado una conferencia, El pensamiento político de la España de hoy, en el Ateneo madrileño, feudo azañista, en la que acusa al jefe del Gobierno de utilizar procedimientos inquisitoriales propios de un dictador (El pensamiento político de la España de hoy).

42 Publicado en El Norte de Castilla, de Valladolid; La Voz de Cantabria, de Santander y El Adelanto, de Salamanca, entre otros periódicos de provincia.

${ }^{43}$ Previsto en el artículo 121 de la Constitución.
} 
su deber de justicia, no tendrá más remedio que someter a control de constitucionalidad la Constitución y «unas leyes adyacentes en las que se vulneran los preceptos mismos que ella establece».

Atribuye al Gobierno, al que no duda en calificar de «sedicente revolucionario», un lógico temor al Tribunal, sabedor de que éste no puede consentir que prevalezcan no sólo acuerdos ministeriales anticonstitucionales, despóticos y arbitrarios, ni tampoco acuerdos parlamentarios, y leyes votadas en Cortes, igualmente arbitrarias, despóticas e injustas. Y se pregunta:

«.. ¿O es que no hay argucia de despotismo que cuando la Constitución veda las confiscaciones, pueda cohonestar las de los bienes de la Compañía de Jesús o las de las fincas de la llamada grandeza? Se hace en nombre de una pretendida revolución y ahí reside el problema de la República que ha querido hacer, a un tiempo, una revolución y una Constitución que la encauce y la entrene. El error ha estado en haber querido hacer una revolución constitucional o una Constitución revolucionaria, como si revolver sea construir...»

Unamuno está convencido de que el pueblo español que votó la República o, mejor, que votó contra la Monarquía y la Dictadura, no pedía semejante revolución, aunque la pidiese una parte de él. El artículo concluye así:

«... Y que no se venga con mandangas de fascismo, de dictadura o de lo que sea. España está entregada a la más lamentable anarquía, a luchas de supuestas clases, a luchas de comarcas, a luchas de confesiones. Y si ha de constituirse algo, ha de ser sobre el sentimiento de justicia, que no es venganza ni represalia, y si ha de garantizarse lo constituido, ha de ser sin hurtar nada al examen de la constitucionalidad...»

\section{Conclusión}

A partir de su elección como diputado a Cortes por Salamanca, don Miguel de Unamuno asume que está metido hasta el cuello en las aguas de sus íntimas guerras civiles.

Le esperan dos años de reflexión y de profecías; de algunas esperanzas y grandes desencantos.

Va a servirse de la pluma y la palabra para decir sus verdades. Se recorta el perfil de un hombre que, al no ser de partido, se encuentra, a conciencia, políticamente desubicado.

Es nada menos que todo un hombre, que no hace mucho regresó del destierro decretado por la dictadura de Primo de Rivera. Es el referente intelectual más alto de la cultura española. Un hombre próximo a la ju- 
bilación, miembro de una generación que había sentido como ninguna otra el dolor de España. Un ensoñador idealista y romántico, que recela, en general, de los políticos.

Durante el periodo constituyente republicano va a erigirse una vez más en «excitator Hispaniae». No está dispuesto a expedir recetas, ni siquiera a proponer soluciones. Lo suyo es un obsesivo e incesante apremio a reflexionar. Estará en las Cortes, pero sobre todo estará en la vida. Por eso, cuando su voz y su palabra no resuenen en el hemiciclo o en la tribuna pública, su pluma se comprometerá con la sociedad española, a través del artículo periodístico.

La lengua española, la unidad nacional y la cuestión religiosa, constituirán una sagrada trinidad para la sensibilidad de Unamuno. Cualquier ataque o restricción a ella, lo considerará como una agresión a la sustancia intrahistórica de España.

Unamuno, siguiendo las teorías idealistas sobre el lenguaje, considera la lengua como la sangre del espíritu, y el español como el mejor instrumento de unión y universalización de España.

Su defensa de la unidad de España - bien aleccionadora para los tiempos que hoy corren - es tan apasionada y concluyente como la de la Lengua española como vehículo universal de cultura y proyección de vascos, catalanes y gallegos. Y no cederá, aunque no le hagan caso, en sus enmiendas parlamentarias para que el castellano sea el eje nuclear de comunicación y de enseñanza.

Recela ampliamente de los planteamientos autonomistas, no por sí mismos, sino porque no responden ni a una descentralización racional, ni a la realidad histórica, sino a intereses egoístas de los nacionalismos que se le antojan desintegradores y excluyentes.

Ante la Constitución republicana adopta una actitud que, cuando no es irónica, resulta abiertamente hostil. Frente a la Constitución formal — «Constitución de papel»- opone la Constitución sustancial, que es la histórica e intrahistórica.

Hace profesión de fe liberal y, por lo mismo, rechaza el sectarismo de aquella República, la prepotencia despótica de Azaña, quien en la Sesión del 13 de octubre de 1931, proclamó que España había dejado de ser católica, y a quienes son responsables de la Ley de Defensa de la República y de la disolución de la Compañía de Jesús, y confiscación de sus bienes, al amparo del artículo 26 de la Constitución republicana.

Este desdén hacia la República, que él contribuyó a traer, alcanzará clímax de descalificación en 1933, cuando solicita, el 12 de septiembre, a través de la prensa, la intervención del Tribunal de Garantías Constitucionales para que revise la Constitución. 